\title{
Modeling reaction-diffusion processes within catalyst washcoats: \\ I. Microscale processes based on three-dimensional reconstructions
}

\author{
Canan Karakaya $^{\mathrm{a}}$, Peter J. Weddle ${ }^{\mathrm{a}}$, Justin M. Blasi ${ }^{\mathrm{a}}$, David R. Diercks ${ }^{\mathrm{b}}$, \\ Robert J. Kee ${ }^{\mathrm{a}, *}$ \\ ${ }^{a}$ Mechanical Engineering Department, Colorado School of Mines, Golden, CO 80401, \\ USA \\ ${ }^{b}$ Metallurgical and Materials Engineering Department, Colorado School of Mines, \\ Golden, CO 80401, USA
}

\begin{abstract}
This paper develops a detailed analysis of reaction-diffusion processes within a porous rhodium-alumina catalyst washcoat. Focused-ion-beam-scanningelectron-microscope (FIB-SEM) techniques are developed and applied to reconstruct the actual catalyst-support microstructure. Three-dimensional transport processes within washcoat micro-pore structures are modeled using a dimensionless representation of reaction and diffusion rates based on the Damköhler number. Three-dimensional computational solutions for particular porous microstructures are modeled and interpreted. In a companion paper, these microstructural results are used to assist development of largerscale models that can be incorporated into reactor-scale simulations.
\end{abstract}

Keywords: Catalyst washcoat, Tomography, Pore microstructure,

\footnotetext{
*Corresponding author. Tel: +1-303-273-3379.

Email address: rjkee@mines.edu (Robert J. Kee)
} 
FIB-SEM, Reaction-diffusion modeling, Porous media

1

2

\section{Introduction}

The objective of this paper is to develop new qualitative and quantitative understanding of reaction-diffusion processes within catalytically active porous washcoats. At the microscale, catalyst washcoats are geometrically complex. Although notional models such as packed spheres can be qualitatively useful, they certainly do not represent the actual catalyst microstructure. At the reactor scale, models invariably represent the effective catalyst area as a multiplicative function of the geometrical surface area of the channel walls [1-3]. In other words, because the washcoat is porous, the effective catalyst area can be significantly larger than the channel wall area. Following the nomenclature of Deutschmann, et al. [2], the multiplicative factor may be called $F_{\text {cat,geo }}$. Albeit with knowledge of measured properties such as porosity, BET surface area, and chemisorption characteristics, the effective catalyst area is usually adjusted empirically. Moreover, $F_{\text {cat,geo }}$ is often taken to be a constant, independent of changes in reactor operating conditions. The results in this paper show that characteristics such as effective area and pore effectiveness are strong functions of the reaction chemistry and the pore microstructure.

This paper is composed of two primary elements. First, a focused-ionbeam-scanning-electron-microscope (FIB-SEM) method is developed and applied to reconstruct the washcoat microstructure from a commercial Rh$\gamma \mathrm{Al}_{2} \mathrm{O}_{3}$ partial-oxidation catalyst monolith. The present study is based upon the catalyst shown in Fig. 1. Reconstruction results reveal microstructures, 
with complex crack- and crevice-like features. Second, using the FIB-SEM reconstructions, three-dimensional computational models are developed to simulate reaction-diffusion processes within the microstructural features. Seeking some generality, the models are implemented in dimensionless form using a characteristic Damköhler number.

A companion paper [4] is devoted to using the microstructural results from the present study to inform large-scale models that can be practically incorporated into full reactor-scale models. The macro-scale models are based on more traditional concepts such as effectiveness factors and Thiele moduli.

[Figure 1 about here.]

Porous washcoats enable the dispersion of active metal (e.g., Pt, Pd, $\mathrm{Rh}, \mathrm{Ni}$ ) with high surface-area-to-volume ratios. However, in designing and synthesizing the porous microstructure, a compromise must often be made between high surface area and internal diffusion limitations within the washcoat. Small pores within the catalyst (on micro and nano scale) present high diffusive resistance from the high frequency collisions between the reactants and the pore wall. At this scale, the diffusive resistance within a pore is mainly Knudsen diffusion [5]. An optimum washcoat design compromises between the gaseous diffusion rates and the accessible catalytic surface area.

\subsection{Prior research}

Detailed modeling of catalytic surfaces has been pursued in previous studies that incorporate three-dimensional representations of the physical catalyst structures. Local variations are determined by simulating the threedimensional pore volumes, which may be either computer generated or re- 
constructed from the actual catalyst. The computer-generated models synthesize three-dimensional random networks of catalyst support structures [69]. The pore-size distributions are obtained experimentally using a nitrogen absorption measurements or mercury porosimetry, while SEM and TEM images are used to determine the particle and pore sizes [6, 9]. Reconstructed models use recent advances in microscopy, enabling three-dimensional imaging of the porous catalytic materials at high resolution [10-14]. Methods for high-resolution microscopy include X-ray tomography [15-20] or FIBSEM techniques [21-26] to reconstruct the microporous structure of the catalysts. The images are also used to explore the influence of the reaction rates and effective diffusions within the porous media, improve the accuracy of the chemical-kinetic models, and optimize the design of the washcoat structure [27]. Detailed simulations resolve the local variations in temperature and species concentrations, which can lead to understanding complex catalyst behavior such as deactivation and hot-spot formation [8].

Although FIB-SEM techniques have been used to characterize a variety of samples $[13,14,28-36]$, the application of this technique on highly porous media is relatively new and challenging. Prill et al. [37, 38] used a FIB-SEM technique for 3D reconstruction of a highly porous media and reported that, unlike the batteries and dense surfaces with less porosity, the interpretation of the FIB-SEM data are quite difficult due to the "shine-through" artifacts. They developed an algorithm for post-processing of the images where these shine-through artifacts were corrected after imaging. Salzer et al. [31] presented a similar approach on a highly porous monolithic foam-like silica material. Because the threshold between the fill material and solid was not 
clear in the FIB-SEM image, a postprocessing algorithm was developed to sharpen phase contrast by adaptive local thresholding.

\section{Three-dimensional imaging}

\subsection{Sample preparation}

The selected porous sample for this study is a commercial catalyst, which was designed for fuel reforming technologies at the industrial level. Figure 1 illustrates the $\mathrm{Rh}-\gamma \mathrm{Al}_{2} \mathrm{O}_{3}$ catalyst washcoated onto a 900 cpsi (cells per square inch) monolith made of cordierite (supplied by Umicore AG). The monolith structure has square flow channels that are approximately $0.77 \mathrm{~mm}$ on each side [39]. The washcoat varies between $5-10 \mu \mathrm{m}$ on the $60 \mu \mathrm{m}$ thick cordierite monolith walls.

A sample pretreatment method was developed to create high-quality FIB-SEM images with good contrast between the epoxy and the washcoat. A mixture of 98 wt\% low viscosity epoxy (Buhler) and 2 wt\% conductive polymer (poly(3,4-ethylenedioxythiophene)-poly(styrenesulfonate) from Sigma Aldrich) was prepared. The viscosity was further decreased by adding 3-5 mL acetone to the $25 \mathrm{~mL}$ mixture. At such low viscosity, the epoxy can sufficiently impregnate even the smallest pores.

The sample was embedded in the conductive epoxy mixture under vacuum conditions to avoid bubbling. A custom vacuum apparatus was designed for this purpose. The sample was placed in a small volume $(100 \mathrm{ml})$ erlenmeyer flask and evacuated until the pressure was below 5 mbar. Once the volume was fully evacuated the conductive epoxy mixture was introduced through a capillary tube. The sample was dried at $35^{\circ} \mathrm{C}$ for $12 \mathrm{~h}$. 
[Figure 2 about here.]

The final sample formed a thick epoxy layer ( $\leq 1 \mathrm{~mm})$. The excess epoxy layer first was removed mechanically using a sand paper until the epoxy layer on the top of the surface was approximately $100 \mu \mathrm{m}$. The surface cleaning was completed by using a cross-section polisher (JEOL IB-09010CP). The cross-section polisher uses an argon beam to controllably mill the specimen surface. The accelerating voltage was $6 \mathrm{kV}$ and the milling rate was $10 \mu \mathrm{m}$ per hour. After these preparations, the specimen was ready for the threedimensional FIB-SEM imaging.

\subsection{FIB-SEM instrument}

Three-dimensional imaging was accomplished using an FEI Helios 600i DualBeam instrument using FEI's Slice and View software. A 30 kV Ga-ion beam operating at $65 \mathrm{nA}$ was used to remove 300 slices of $100 \mathrm{~nm}$ each, covering a total thickness of $30 \mu \mathrm{m}$. Between each slice, a SEM image was captured by the thru-lens detector using a $5 \mathrm{kV}$ accelerating voltage and 1.4 nA beam current. The detector and image settings were adjusted to optimize the contrast between the catalyst and epoxy phases. Images were collected at a $52^{\circ}$ angle relative to the milling direction with tilt correction employed to adjust the aspect ratio to that for a $90^{\circ}$ incidence. The horizontal field of view was $46.5 \mu \mathrm{m}$ with each pixel being approximately $23 \mathrm{~nm}$ per side.

The FIB-SEM experiments produce approximately three hundred twodimensional slices that account for $26.7 \mu \mathrm{m} \times 13.8 \mu \mathrm{m} \times 37.4 \mu \mathrm{m}$ of catalyst volume. The original FIB-SEM images are rendered on a gray-scale and are systematically notch-filtered and exposure-corrected to easily identify 
the difference between epoxy and catalytic material. An adaptive thresholding technique is used to discriminate between phases. The black-and-white, filtered, FIB-SEM images indicate the location of alumina in white and infiltrating epoxy in black. Figure 2 illustrates a typical FIB-SEM slice before and after filtering.

The quality of the FIB-SEM data is greatly enhanced by filling the micropore structures with an appropriate material to create good contrast between the pore and the catalyst material. Filling the pores also assists in decreasing the amount of curtaining in the images from the FIB milling. The fill material should have a different density than the catalytic material to obtain a good contrast and it should be conductive so that the quality of the electron beam images is not compromised.

\section{Reconstruction}

The FIB-SEM images are reconstructed into a complete three-dimensional object using the Mimics software. ${ }^{1}$ Due to the nature of the machining process, filtering, and the three-dimensional generation, some sequential images are not perfectly aligned and some of the gray-scale is not easily identifiable as epoxy or catalytic material. With these minor adjustments in mind, it is reasonable to assume some smoothing should be applied to the reconstructed three-dimensional object. Wiedemann et al. [40] performed similar procedures to three-dimensionally reconstruct cathode microstructures for lithium-ion batteries.

\footnotetext{
${ }^{1}$ Materialize, NV; Leuven, Belgium; http://www.materialise.com.
} 
[Figure 3 about here.]

Figure 3 illustrates the smoothed, reconstructed, three-dimensional catalyst with various undulations, pores, and crevices on the surface. The reconstructed catalytic sample is so complex that rendering the full volume mesh and performing simulations is computationally very expensive. To reduce the size of the mesh, and thus the computational time, several representative surface pores where selected from the microstructure and modeled separately for in-depth study. Each of the pores are unique in structure, depth, and surface area. The pore's three-dimensional surface meshes are exported from Mimics in STereoLithography (STL) format, which interfaces well with finite-volume meshing software.

[Figure 4 about here.]

Figure 4 illustrates the pore volumes for five pores that are extracted from the reconstructed catalyst sample. The figure also illustrates the surface area for each of the pores with respect to depth. As illustrated in Fig. 4, Pore Volume 1 is a structure with high surface area near the pore entrance that decreases deeper into the pore. The surface area of Pore Volume 2 is more uniformly distributed along its depth and resembles a crevice-like structure. Pore 2 does have a large section near the bottom that is significantly restricted from the rest of the pore volume. Pore Volume 3 presents a similar crevice-like feature with large surface area concentrated at the bottom of the pore. Pore Volume 4 has long spindly structures connecting the top of the pore to the majority of the active catalytic area near the bottom of the pore. Pore Volume 5 is the shortest pore with the least surface area of the five 
pores considered in this study. The surface-area versus depth graphs (Fig. 4) further illustrate the uniqueness of the selected pores and give an idea of where possible pinch points may exist. However, the graphs alone do not express the tortuosity that is evident in the three-dimensional renderings.

To study pore effectiveness alone, without including the catalytic activity occurring on the washcoat's external surfaces, each reconstructed pore is isolated from the top-surface structure and the pore opening is cut as a planar surface. Additionally, any small fragments of pore volume captured in the reconstruction that are not connected to the external surface do not participate in the reaction and are therefore removed from the computational domain during the meshing process.

Although only five pore volumes are selected for detailed study, these pores represent qualitatively the range of behaviors that can be observed throughout the washcoat. In principle, many more pores could be reconstructed for the purpose of identifying statistical characteristics across a wide variety of the random pores. However, the time and cost to do so is prohibitively high.

\section{Microstructural modeling}

Although the microstructural geometry is highly complex (cf., Fig. 4), the reaction-diffusion model is greatly simplified. The simplicity is beneficial in two ways. First, the results can be generalized in terms of dimensionless groups such as the Damköhler number. Second, the computation time is greatly reduced compared to a model that considers detailed multi-step reaction kinetics and high-fidelity molecular transport. However, as discussed in 
Section 4.3, the modeling approach can be extended to more complex global reactions.

The model assumes only two generic gas-phase species, A and B. The catalytic chemistry is represented simply as a first-order irreversible reaction $\mathrm{A} \rightarrow \mathrm{B}$, with a rate constant of $k$. Any possible gas-phase reaction is neglected. Within the pore volume, steady-state gas-phase diffusion of A is represented as

$$
\nabla \cdot\left(D_{\text {pore }} \nabla C_{\mathrm{A}}\right)=0,
$$

where $C_{\mathrm{A}}$ represents the concentration of $\mathrm{A}$ and $D_{\text {pore }}$ is an pore diffusion coefficient. Because the length scale of the pore microstructure is so small, the pore diffusion, $D_{\text {pore }}$, may be a combination of Knudsen and bulk diffusion [41]. This formulation neglects any pressure variations and convective fluid flow within the microstructure, which is usually a good assumption in microscale pore-volume features. The active catalyst is assumed to be uniformly distributed over the entire surface of the pore volume. Finally, the model assumes isothermal conditions.

Equation 1 is an elliptic partial differential equation whose solution requires boundary conditions. At the gas-surface interfaces within the porevolumes the boundary condition is

$$
\mathbf{n} \cdot D_{\text {pore }} \nabla C_{\mathrm{A}}=k C_{\mathrm{A}},
$$

where $\mathbf{n}$ is the outward-pointing normal unit vector at the catalyst surface. As may be inferred from Fig. 5, there may be on the order of 10,000 finitevolume surface elements where Eq. 2 applies. At the top of the pore volume (where the pore volume interfaces with the flow channel), the mole fraction 
226

of A is assumed to be unity. In some circumstances, a particular pore-volume feature may intersect with the edge of the full three-dimensional volume (i.e., Fig. 3). In this case, symmetry boundaries are enforced.

To assist generalizing performance metrics, the model can be put into dimensionless form using the characteristic scale factors. The length scale is defined as

$$
L=\frac{V_{\mathrm{p}}}{A_{\mathrm{s}}},
$$

where $V_{\mathrm{p}}$ and $A_{\mathrm{s}}$ are the pore volume's volume and surface area, respectively. Although the geometry is complex, these values can be easily extracted from the three-dimensional reconstructions. The characteristic concentration is taken to be $C_{\mathrm{A}, \text { top }}$, which is assumed to be pure species $\mathrm{A}$ at the top of the pore. Using these scale factors, the dimensionless variables are

$$
\hat{C}_{\mathrm{A}}=\frac{C_{\mathrm{A}}}{C_{\mathrm{A}, \text { top }}}, \quad \hat{x}=\frac{x}{L}, \quad \hat{y}=\frac{y}{L}, \quad \hat{z}=\frac{z}{L} .
$$

Upon transformation with these scale factors, the dimensionless form of the conservation equation and boundary condition can be expressed as

$$
\nabla^{2} \hat{C}_{\mathrm{A}}=0,
$$

$$
\mathbf{n} \cdot \nabla \hat{C}_{\mathrm{A}}=\operatorname{Da} \hat{C}_{\mathrm{A}} .
$$

A single dimensionless parameter, the Damköhler number, appears in the boundary condition,

$$
\mathrm{Da}=\frac{k L}{D_{\text {pore }}} .
$$

The Damköhler number $\mathrm{Da}$ is parameterized by the first-order kinetic rate constant $k$, the pore diffusion coefficient $D_{\text {pore }}$, and the length scale, $L$. High reaction rates, compared to diffusion rates, lead to high Damköhler numbers. 
Equation 7 unambiguously defines the Damköhler number that is used in the present study. However, it may be noted that alternative definitions of the Damköhler number are used in the chemical engineering literature, with their precise definitions depending on the context. For example, it is common to define a Damköhler number that represents the competition between diffusive resistance associated with the monolith channel-flow mass-transfer boundary layer and net the reaction rate at the washcoat interface. Because the present study is concerned entirely with reaction-diffusion behavior within pores, and not concerned with the monolith channel flow, such a Damköhler number definition is not appropriate.

\subsection{Computational solution}

Although the pore volumes are geometrically complex, the governing conservation equation is linear. The equation is solved on a finite-volume mesh using the ANSYS FLUENT software.

A finite-volume mesh for each reconstructed pore volume is generated using the ANSYS TGRID software ${ }^{2}$ with a cut-cell meshing scheme. Cutcell meshing adapts to the surface of the pore volume and increases in mesh density near edge interfaces. Figure 5 illustrates the cut-cell meshing scheme for one of the pores. With geometries as complex as the pore volumes, highly skewed or otherwise poor mesh volumes can be problematic. By using TGRID's internal re-meshing and node optimization algorithms, low-quality mesh volumes are significantly decreased or eliminated. A typical pore contains about 500,000 finite-volume cells, with some pores requiring around a

\footnotetext{
${ }^{2}$ ANSYS, Inc; Canonsburg, PA; http://www.ansys.com.
} 
million cells.

[Figure 5 about here.]

Once a mesh is generated, the equations are solved using the ANSYS Fluent software. Boundary conditions (Eq. 6) must be assigned to all gas-surface interfaces. The present study models each of the five selected pore volumes with five different values of Damköhler number $\left(10^{-5} \leq \mathrm{Da} \leq\right.$ $\left.10^{-1}\right)$. The computation times depend on the Damköhler number, with lower Damköhler numbers requiring more computation because more of the pore geometry is catalytically available. Simulation times varied between thirty minutes to forty hours on sixteen parallel processors.

The output metrics for each pore volume are evaluated from the ANSYS FLUENT solution through a User-Defined-Function (UDF). The UDF is written to compute the area-normalized flux of the product species out of the pores at their uppermost faces. Additionally, the reaction rates and mesh statistics are evaluated on all the reactive surfaces within the pore volume to determine the depths of reaction.

As in most large-scale finite-volume computational simulations, it is important to demonstrate that the results are independent of the mesh resolution. This study measured mesh independence in terms of the net product flux from a pore volume. Especially for the lowest Damköhler numbers, where most of the pore surfaces are catalytically available, the solutions can depend significantly on mesh resolution. When mesh resolution is inadequate, the product fluxes tend to oscillate and not reach a steady asymptotic result. The meshes used for the reported results are always refined to the point that the product fluxes are steady and independent of the meshing. 


\subsection{Pore performance metrics}

Once a solution is found for a particular pore volume, summary performance metrics can be evaluated. Consider first the product species flux (here, species B) emerging from the pore opening, where the pore meets the flow channel. The flux can be evaluated as

$$
J_{\mathrm{p}}=\frac{\int_{\text {top }} D_{\text {pore }} \nabla C_{\mathrm{B}} \cdot \mathbf{n} \mathrm{dA}}{A_{\mathrm{p}}},
$$

where $A$ is the surface defining the pore-volume opening to free-stream flow, and $A_{\mathrm{p}}$ is the total pore-volume opening area. The integral is needed because the solution is represented locally on the discrete mesh network.

It is useful to normalize pore flux by the flux that would be produced by a catalytic flat plate with the same surface area as the pore-opening area. Continuing to assume first-order kinetics and fixed composition of species A, the flat-plate flux can be written as

$$
J_{\mathrm{o}}=C_{\mathrm{A}, \mathrm{top}} k
$$

The normalized pore flux $\Gamma_{\mathrm{p}}$ follows as

$$
\Gamma_{\mathrm{p}}=\frac{J_{\mathrm{p}}}{J_{\mathrm{o}}}=\frac{\int_{\text {top }} D_{\text {pore }} \nabla C_{\mathrm{B}} \cdot \mathbf{n} \mathrm{dA}}{C_{\mathrm{A}, \max } k A_{\mathrm{p}}} .
$$

In dimensionless terms, which is the form delivered from the three-dimensional simulations, the normalized effective product flux can be written as

$$
\Gamma_{\mathrm{p}}=\frac{1}{\mathrm{Da}} \frac{\int_{\mathrm{top}} \nabla \hat{C}_{\mathrm{B}} \cdot \mathbf{n d} \hat{\mathrm{A}}}{\hat{A}_{\mathrm{p}}} .
$$

The normalized flux compares the catalytic performance of a pore to an equivalent-area flat washcoat. A value of unity for $\Gamma_{\mathrm{p}}$ indicates that a pore 
317

is producing an equivalent product species flux as a flat catalytic surface of the same area as the pore opening.

Another measure of pore performance is the pore effectiveness $\eta_{\mathrm{p}}$, which is evaluated as

$$
\eta_{\mathrm{p}}=\Gamma_{\mathrm{p}} \frac{A_{\mathrm{p}}}{A_{\mathrm{s}}}
$$

The pore effectiveness measures the flux of product leaving the pore volume compared to the maximum possible flux if all catalytic surfaces were exposed to free stream conditions. The pore effectiveness is unity if there are no masstransport limitations within the pore.

Yet another relevant measure of washcoat performance is the pore depth beyond which any additional catalyst is unused. If reaction rates are high (relative to diffusion), then most reaction occurs near the pore opening and relatively shallow pores are appropriate. The present study measures the pore depth $\hat{Z}_{95}$ by which $95 \%$ of the catalytic reaction has been completed.

\subsection{Possible extensions}

The present model is based upon a single, irreversible, first-order reaction $(\mathrm{A} \rightarrow \mathrm{B})$, which enables the generalization in terms of a Damköhler number as a single dimensionless parameter. However, if the chemistry and transport can be represented with single parameters, the approach can be extended to more complex chemistry. Consider, for example, steam reforming that might be expressed globally as

$$
\mathrm{CH}_{4}+\mathrm{H}_{2} \mathrm{O} \leftrightarrows 3 \mathrm{H}_{2}+\mathrm{CO}
$$

$$
\mathrm{CO}+\mathrm{H}_{2} \mathrm{O} \leftrightarrows \mathrm{H}_{2}+\mathrm{CO}_{2}
$$


Assume further that the process is rate-limited by the methane activation, with the water-gas-shift reaction remain in equilibrium. In this case, the single reaction-rate parameter is the forward rate constant for Eq. 13. Other parameters include the equilibrium constants, which depend on known gasphase thermodynamics. Empirical representations of a steam-reforming rate expression are available (e.g., [42-44]). Additionally, modeling the microstructural transport problem also requires at least pore diffusion coefficients for the four gas-phase species. A characteristic Damköhler number can be defined as a function of the ratio of the pre-exponential factor for forward rate constant associated with reaction 13 and the pore diffusion coefficient. The model must solve for four species gas-phase species, not two as in the present model. The local catalytic species production rates depend on the reaction orders in the empirical rate expression and the local species composition through the pore volume.

In principle, the model can also accommodate large elementary-step reaction mechanisms (e.g., [45-47]) and the software is in place to do so. However, the computational problem is very much larger. In addition to needing more gas-phase species, the reaction mechanisms also involve surface adsorbates. Moreover, with detailed chemistry there is no possibility to generalize the results in terms of a single parameter.

\section{Illustrative results}

[Figure 6 about here.]

[Figure 7 about here.] 
[Figure 8 about here.]

[Figure 9 about here.]

[Figure 10 about here.]

Figures 6 - 10 show the influence of the Damköhler number on pore performance within different pore volumes. Despite the qualitative shape differences within the pores, similar Damköhler numbers produce qualitatively similar species profiles. For example, species-A penetration depth is reasonably well characterized by the Damköhler number within all of the pore volumes. This is a desirable result in the sense that the important aspects of the pore-scale reaction-diffusion processes may be represented in a dimensionless setting that only weakly depends on the detailed pore-volume microstructural geometry. At relatively high Damköhler numbers, the reaction is mainly concentrated at the pore openings leaving most of the catalytic area deeper in the pores underutilized. However, as the Damköhler number decreases the reaction is able to penetrate further into the pores. In this case, the net reaction can depend on local diffusion resistances, such as small necking regions.

The pore-volume simulations illustrate the influences of local geometric features within pores. Figure 6 shows that Pore 1 has a highly tortuous structure. As the Damköhler number decreases, Pore 1 contains more of reactant species $\mathrm{A}$. The species profiles indicate that as the kinetic rate is decreased relative to the effective diffusion rate (low Damköhler number) the reactant is able to reach more of the available catalytic surface. However, 
there are significant choke points in Pore 1 near the bottom of the pore, which limit access to some catalyst area.

Figures 7 and 8 illustrate species concentration simulation results for Pores 2 and 3 respectively. Both of these pores contain significant choke points. The simulation results indicate that the apparent pore tortuosity greatly influences pore performance. Pore 2 (Fig. 7) and Pore 4 (Fig. 9) present two different species rates of progress as a function of Damköhler number. Pore 2 is characterized by a relatively open crevice-like structure. Thus, the diffusion resistance is relatively low, enabling the reactant to penetrate deep into the pore even at relatively high Damköhler numbers. In Pore 2 a small change in diffusion rate can significantly increase the effective utilization of catalytic surface area. On the other hand, Pore 4 is characterized by long thin features that connect the opening of the pore to the deeper catalytic surface areas. These thin capillary-like features restrict the reactant from penetrating into the pore and subsequently limit the effective surface area. Thus, Pore 4 is less sensitive to diffusion rate as compared to Pore 2. The Pore 5 (Fig. 10) diffusion resistances are similar to those in Pore 2. These pores are generally more open, without significant interior choke points, where the reactant can penetrate deep into the volume at higher Damköhler number. Because Pore 5 is quite shallow compared to the other four pore volumes, accessing all the available catalytic surface area is easier.

[Figure 11 about here.]

Figure 11 illustrates some quantitative performance measures for the five pore-volume simulations. The three plots show the effective normalized pore 
flux $\Gamma_{\mathrm{p}}$ (top), pore effectiveness $\eta_{\mathrm{p}}$ (middle), and reaction depth $\hat{Z}_{95}$ (bottom) as functions of Damköhler number. Some expected trends are apparent. For high Damköhler numbers (relatively fast reaction) all measures tend toward zero (or unity in the case of $\Gamma_{\mathrm{p}}$ ). Conversely, as the Damköhler number decreases (relatively high diffusion), reaction depth approaches $100 \%$, pore effectiveness tends toward unity, and the respective normalized fluxes diverge from one another. This suggests the morphological differences between pores are largely only relevant to flux performance at low Damköhler numbers. It appears that while all the pore volumes sampled in this study produce nearunity effectiveness and near-100\% reaction depth at low Damköhler numbers, there are clear performance differences from one pore to another. Pore 1 produces approximately 70 times the effective normalized product species flux of a flat plate, while Pore 5 delivers only a factor of approximately 18 . Referencing the pore-volume reactive surface area measures in Table 1, it is clear this effect is not simply a function of available catalytic area but also of more complex morphological differences (e.g., pinch points, pore-like features, crevice-like structures).

[Table 1 about here.]

\section{Summary and conclusions}

The catalyst washcoats from a commercial $\mathrm{Rh}-\gamma \mathrm{Al}_{2} \mathrm{O}_{3}$ partial-oxidation monolith are reconstructed using focused-ion-beam-scanning-electron-microscopy.

The three-dimensional reconstructions reveal complex microscale surface and pore morphology. The micro-morphology is quite different from notional models based on isotropic porous media or arrays of cylindrical pores. The 
structure of individual pores can vary significantly, ranging from crevice-like features to tortuous capillary-like features.

New models are developed and applied to investigate reaction-diffusion processes within reconstructed pore volumes. Assuming first-order kinetics and constant diffusion coefficients, the problem can be cast in dimensionless variables with a Damköhler number emerging as a characteristic dimensionless group. The three-dimensional reaction-diffusion problem is solved within the geometrically complex pore structures. In addition to predicting local concentration fields and reaction rates within the pore volumes, the model also predicts summary information such as net product flux from the pore, pore effectiveness, and reaction penetration depth. These results depend greatly on the Damköhler number.

The paper contributes new quantitative insight about the performance of actual catalyst washcoats. A companion paper [4] uses predicted results from the microscale reconstructed pore volumes to develop macroscale models that can be applied at larger length scales.

\section{Acknowledgements}

The theory and modeling aspects of this research were supported by the Office of Naval Research (N000141210201) and the experimental aspects were supported by the Air Force Office of Scientific Research (FA9550-12-1-0495). We gratefully acknowledge Prof. Scott Barnett (Northwestern University) for advice and assistance in FIB-SEM sample preparation. The FIB-SEM instrument was acquired via a DURIP grant from ONR. 


\section{References}

\section{References}

[1] R.J. Kee, M.E. Coltrin, and P. Glarborg. Chemically Reacting Flow. Wiley, Hoboken, NJ, 2003.

[2] O. Deutschmann. Modeling and Simulation of Heterogeneous Catalytic Reactions: From the Molecular Process to the Technical System. WileyVCH, Weinheim, Germany, 2012.

[3] S. Tischer and O. Deutschmann. Recent advances in numerical modeling of catalytic monolith reactors. Catal. Today, 105:407-413, 2005.

[4] J.M. Blasi, P.J. Weddle, C. Karakaya, D.R. Diercks, and R.J. Kee. Modeling reaction-diffusion processes within catalyst washcoats: II. Macroscale processes informed by microscale simulations. Chem. Engr. Sci., page submitted, 2015.

[5] H.S. Fogler. Elements of chemical reaction engineering. Prentice Hall, Upper Saddle River, NJ, 1992.

[6] P. Koči, F. Štěpánek, M. Kubíček, and M. Marek. Meso-scale modeling of $\mathrm{CO}$ oxidation in digitally reconstructed $\mathrm{Pt} / \gamma \mathrm{Al}_{2} \mathrm{O}_{3}$. Chem. Eng. Sci., 61:3240-3249, 2006.

[7] F.J. Keil. Diffusion and reaction in porous networks. Catal. Today, 53:245-258, 1999. 
[8] M. Behnam, A.G. Dixon, M. Nijemeisland, and E.H. Stitt. Catalyst deactivation in 3D CFD resolved particle simulations of propane dehydrogenation. Ind. Eng. Chem. Res., 49:10641-10650, 2010.

[9] P. Koči, F. S̆tĕpánek, M. Kubíček, and M. Marek. Modeling of micro/nano-scale concentration and temperature gradients in porous supported catalysts. Chem. Eng. Sci., 62:5380-5385, 2007.

[10] G. Hoffmann, A. Rochet, S. Baier, M. Casapu, S. Ritter, F. Wilde, M. Ogurreck, F. Beckmann, and J.-D. Grunwaldt. Ageing effects on exhaust gas catalysts: Microscopic changes captured by X-ray tomography. J. Phys. Conf. Ser., 499:1-11, 2014.

[11] W.K. Epting, J. Gelb, and S. Litster. Resolving the three-dimensional microstructure of polymer electrolyte fuel cell electrodes using nanometer scale X-ray computed tomography. Adv. Funct. Mater., 22:555-560, 2012.

[12] L. Ruffino, R. Mann, R. Oldman, E.H. Stitt, E. Boller, P. Cloetens, M. Dimichiel, and J. Merino. Using X-ray microtomography for characterization of catalyst particle pore structure. Can. J. Chem. Eng., 83:132-139, 2005.

[13] L. Karwacki, D.A. Matthijs de Winter, L.R. Aramburo, M.N. Lebbink, J.A. Post, M.R. Drury, and B.M. Weckhuysen. architecture-dependent distribution of mesopores in steamed zeolite crystals as visualized by FIB-SEM tomography. Angew. Chem. Int. Ed., 50:1294-1298, 2011. 
[14] X. Zhang, H. Ostadi, K. Jiang, and R. Chen. Reliability of the spherical agglomerate models for catalyst layer in polymer electrolyte membrane fuel cells. Electrochim. Acta, 133:475-483, 2014.

[15] J.P. James, H.-W. Choi, and J.G. Pharoah. X-ray computed tomography reconstruction and analysis of polymer electrode membrane fuel cell porous transport layers. Int. J. Hydrogen Energy, 37:18216-18230, 2012 .

[16] L. Zhang, J.M.F. Ferreira, S. Olhero, L. Courtois, T. Zhang, E. Maire, and J. Chr. Rauhe. Modeling the mechanical properties of optimally processed cordierite-mullite-alumina ceramic foams by X-ray computed tomography and finite element analysis. Acta Mater., 60:4235-4246, 2012.

[17] A. Pfang, S. Didas, and G. Tsotridis. X-ray computed tomography of gas diffusion layers of PEM fuel cells: Segmanetation of the microporous layer. J. Power Sources, 235:81-86, 2013.

[18] J. Zecevic, K.P. de Jong, and P.E. de Jong. Progress in electron tomography to assess the 3D nanostructure of the catalysts. Curr. Opin. Solid State Mater. Sci., 17:115-125, 2013.

[19] V. Lee, V. Verejnov, M. West, S. Kundu, D. Susac, J. Strumper, R.T. Atanasoski, M. Debe, and A.P. Hitschcock. Scanning transmission X-ray microscopy of nano structured thin film catalysts for proton-exchangemembrane fuel cells. J. Power Sources, 263:163-174, 2014. 
[20] J.S. da Silva, K. Mader, M. Holder, D. Haberthuer, A. Diaz, M. GuizarSicarios, W.-C. Cheng, Y.Y. Shu, J. Raabe, A. Menzel, and J.A. van Bokhoven. Assessment of the 3D pore structure and individual components of preshaped catalyst bodies by X-ray imaging. ChemCatChem, 7:413-416, 2015.

[21] J.R. Wilson, W.K. Kobsiriphat, R. Mendoza, H.-Y. Chen, J.M. Miller, D.J. Miller, K. Thornton, P.W. Voorhees, S.B. Adler, and S.A. Barnet. Three-dimensional reconstruction of a solid-oxide fuel-cell anode. Nat. Mater., 5:541-544, 2006.

[22] H. Schulenburg, B. Schwanitz, N. Nicolas, G.G. Scherer, A. Wokaun, J. Krbanjevic, R. Grothausmann, and I. Manke. 3D imaging of catalyst support corrosion in polymer electrolyte fuel cells. J. Phys. Chem. C., 115:14236-14243, 2011.

[23] L. Karwacki, D.A.M. de Winter, L.R. Aramburo, M.N. Lebbink, J.A. Post an M.R. Drury, and B.M. Weckhuysen. Architecturedependent distribution of mesopores in steamed zeolite crystals as visualized by FIB-SEM tomography. Angew. Chem. Int. Ed., 50:1294-1298, 2011.

[24] C. Ziegler, S. Thiele, and R. Zengerle. Direct three-dimensional reconstruction of a nanoporous catalyst layer for a polymer electrolyte fuel cell. J. Power Sources, 196:2094-2097, 2011.

[25] B. Pereda-Ayo, J.A. Botas-Echevarria, J. Gonzalez-Casablanca, M.P. Gonzalez-Marcos, and J.R. Gonzalez-Velasco. Characterization of Pt 
and $\mathrm{Ba}$ over alumina waschcoated monolith for NOx storage and reduction NSR by FIB-SEM. J. Power Sources, 228:185-192, 2013.

[26] R. Singh, A.R. Akhgar, P.C. Sui, , K.J. Lange, and N. Djilali. Dual-beam FIB/SEM characterization, statistical reconstruction and pore scale modeling of a PEMFC catalyst layer. J. Electrochem. Soc., 161:415$424,2014$.

[27] V. Novák, E. Ortel, B. Winter, b. Wunz, B. Paul, P. Koči, M. Marek, E. Spiecker, and R. Kraehnert. Prototyping of catalyst pore-systems by a combined synthetic analytical and computational approach:Application to mesoporous $\mathrm{TiO}_{2}$. Chem. Eng. J., 248:49-62, 2014.

[28] B.J. Inkson, M. Mulvihill, and G. Möbus. 3D determination of grain shape in a FeAl-based nanocomposite by 3D FIB tomography. Scr. Mater., 45:753-758, 2001.

[29] L. Holzer, F. Indutnyi, P.H. Gasser, B. Münch, and M. Wegmann. Three-dimensional analysis of porous $\mathrm{BaTiO}_{3}$ ceramics using FIB nanotomography. J. Microsc., 216:84-95, 2004.

[30] M.A. Groeber, B.K. Haley, M.D. Uchic, D.M. Dimiduk, and s. Ghosh. 3D reconstruction and characterization of polycrystalline microstructures using a FIB-SEM system. Mater. Charact., 57:259-273, 2006.

[31] M. Salzer, A. Spettl, O. Stenzel, J.-H. Smatt, M. Lindén, and I. Manke. A two-stage approach to the segmentation of FIB-SEM images of highly porous materials. Mater. Charact., 69:115-126, 2012. 
[32] J.R. Wilson, J.S. Cronin, S.A. Barnett, and S.J. Harris. Measurement of three-dimensional microstructure in a $\mathrm{LiCoO}_{2}$ positive electrode. $J$. Power Sources, 196:3443-3447, 2011.

[33] Y.-C. K. Chen-Wiegart, R. Demike, C. Erdonmez, K. Thornton, S.A. Barnett, and J. Wang. Tortuosity characterization of 3D microstructure at a nano-scale for energy storage and conversion materials. J. Power Sources, 249:349-356, 2014.

[34] H. Iwai, N. Shikazono, T. Matsui, H. Teshima, M. Kishimoto, R. Kishida, D. Hayashi, K. Matsuzaki, D. Kanno, M. Saito, H. Muroyama, K. Eguchi, N. Kasagi, and H. Yoshida. Quantification of SOFC anode microstructure based on dual beam FIB-SEM technique. J. Power Sources, 195:955-961, 2010.

[35] S. Hemes, G. Desbois, J.L. Urai, and B. Schröppel. Multi-scale characterization of porosity in Boom Clay (HADES-level, Mol, Belgium) using a combination of X-ray $\mu$-CT, 2D BIB-SEM and FIB-SEM tomography. Microporous Mesoporous Mater., 208:1-20, 2015.

[36] Y. Katayanagi, T. Shimizu, Y. Hashimasa, N. Matsushita, Y. Yamazaki, and T. Yamaguchi. Cross-sectional observation of nanostructured catalyst layer of polymer electrolyte fuel cell using FIB-SEM. J. Power Sources, 280:210-216, 2015.

[37] T. Prill, K. Schladitz, D. Jeulin, M. Faessel, and C. Wieser. Morphological segmentation of FIB-SEM data of highly porous media. J. Microsc., 250:77-87, 2013. 
[38] T. Prill and K. Schladitz. Simulation of FIB-SEM images for analysis of porous microstructures. Scanning, 35:189-195, 2013.

[39] Claudia Diehm. Catalytic Reforming of Fuels Over Noble MetalCoated Honeycomb Monoliths:Capillary-Based In-Situ Sampling Technique. PhD thesis, Karlsruhe Institute of Technology,Faculty of Chemistry and Biosciences, 2013.

[40] A.H. Wiedemann, G.M. Goldin, S.A. Barnett, H. Zhu, and R.J. Kee. Effects of three-dimensional cathode microstructure on the performance of lithium-ion battery cathodes. Electrochim. Acta, 88(0):580-588, 2013.

[41] F. Zhang, R.E. Hayes, and S.T. Kolaczkowski. A new technique to measure the effective diffusivity in a catalytic monolith washcoat. Chem. Eng. Res. Des., 82(4):481-489, 2004. 8th UK National Heat Transfer Conference.

[42] J. Xu and G.F. Froment. Methane steam reforming, methanation, and water-gas shift: I. intrinsic kinetics. AIChE J., 35:88-96, 1989.

[43] K. Ahmed and K. Foger. Kinetics of internal steam reforming of methane on Ni/YSZ-based anodes for solid oxide fuel cells. Catal. Today, 63:479487, 2000.

[44] K.P. Recknagle, E.M. Ryan, B.J. Koeppel, L.A. Mahoney, and M.A. Khaleel. Modeling of electrochemistry and steammethane reforming performance for simulating pressurized solid oxide fuel cell stacks. $J$. Power Sources, 195:6637-6644, 2010. 
590

591

592

593

[45] C. Karakaya, L. Maier, and O. Deutschmann. Surface reaction kinetics of the oxidation and reforming of $\mathrm{CH}_{4}$ over $\mathrm{Rh} / \mathrm{Al}_{2} \mathrm{O}_{3}$ catalysts. Int. J. Chem. Kinet., in press, 2016. DOI:0.1002/kin.20980.

[46] K. Herrera Delgado, L. Maier, S. Tischer, A. Zellner, H. Stotz, and O. Deutschmann. Surface reaction kinetics of steam and $\mathrm{CO}_{2}-$ Reforming as well as oxidation of methane over nickel-based catalysts. Catalysts, 5:871-904, 2015.

[47] C. Karakaya and O. Deutschmann. Kinetics of hydrogen oxidation on $\mathrm{Rh} / \mathrm{Al}_{2} \mathrm{O}_{3}$ catalysts studied in a stagnation-flow reactor. Chem. Eng. Sci., 89:171-184, 2013. 


\section{List of Figures}

1 A cordierite monolith support (900 cells per square inch, cpsi) with a $\mathrm{Rh}-\gamma \mathrm{Al}_{2} \mathrm{O}_{3}$ catalyst washcoat. The SEM shows a typical FIB-SEM slice from the washcoat. . . . . . . . . . . . . 30

2 A sample of FIB-SEM image for catalyst reconstruction (top) and the filtered image used for three-dimensional reconstruction (bottom). . . . . . . . . . . . . . . . . 31

3 Three-dimensional reconstruction of a small section of catalyst washcoat. . . . . . . . . . . . . . 32

4 Microstructural pore volumes for five selected pores and their respective surface areas as functions of depth. . . . . . . . . . 33

5 An example of a generated cut-cell mesh created in ANSYS T-GRID for Pore Volume 3. . . . . . . . . . . . . . . . . . . . 34

6 Predicted reactant mole fractions within Pore Volume 1 at different Damköhler numbers. . . . . . . . . . . . . . . . 35

7 Predicted reactant mole fractions within Pore Volume 2 at different Damköhler numbers. . . . . . . . . . . . . . . . . 36

8 Predicted reactant mole fractions within Pore Volume 3 at different Damköhler numbers. . . . . . . . . . . . . . 37

9 Predicted reactant mole fractions within Pore Volume 4 at different Damköhler numbers. . . . . . . . . . . . . . . . . 38

10 Predicted reactant mole fractions within Pore Volume 5 at different Damköhler numbers. . . . . . . . . . . . . . . . . . . 39

11 Performance metrics for simulations of the five pore volumes. For a range of Damköhler numbers, the normalized pore flux $\Gamma_{\mathrm{p}}$ (top), the pore effectiveness $\eta_{\mathrm{p}}$ (middle), and reaction depth $\hat{Z}_{95}$ (bottom) are presented. . . . . . . . . . . . 40 


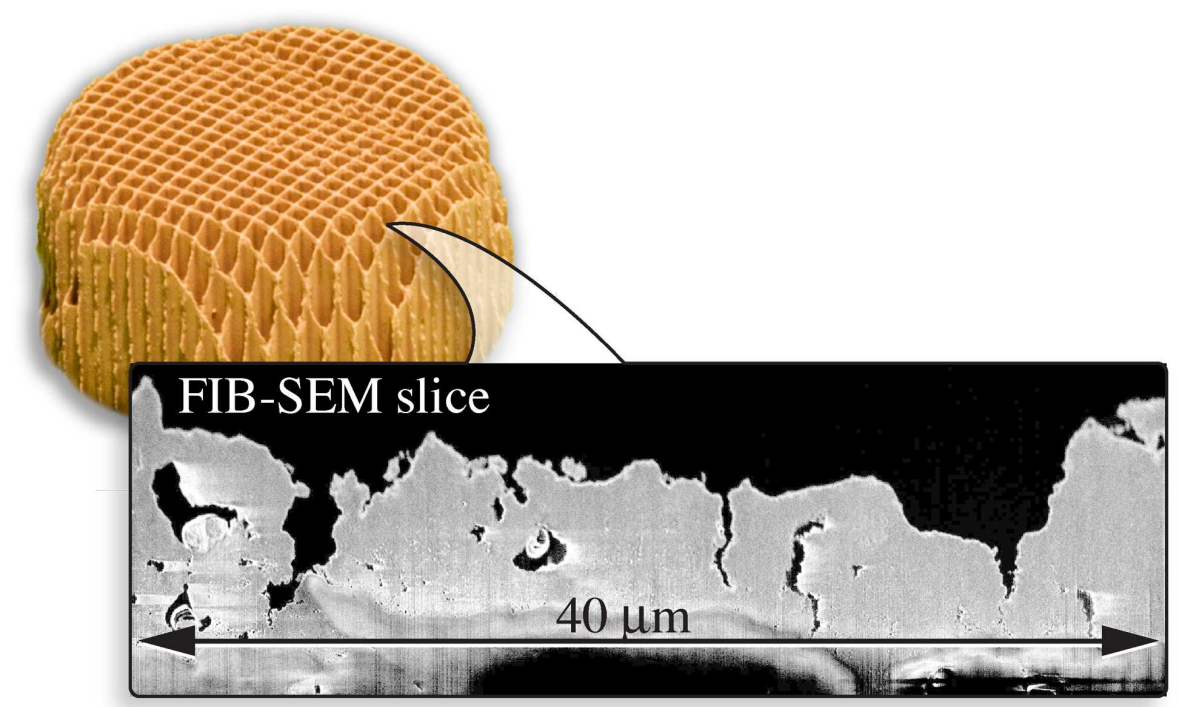

Figure 1: A cordierite monolith support (900 cells per square inch, cpsi) with a $\mathrm{Rh}-\gamma \mathrm{Al}_{2} \mathrm{O}_{3}$ catalyst washcoat. The SEM shows a typical FIB-SEM slice from the washcoat. 

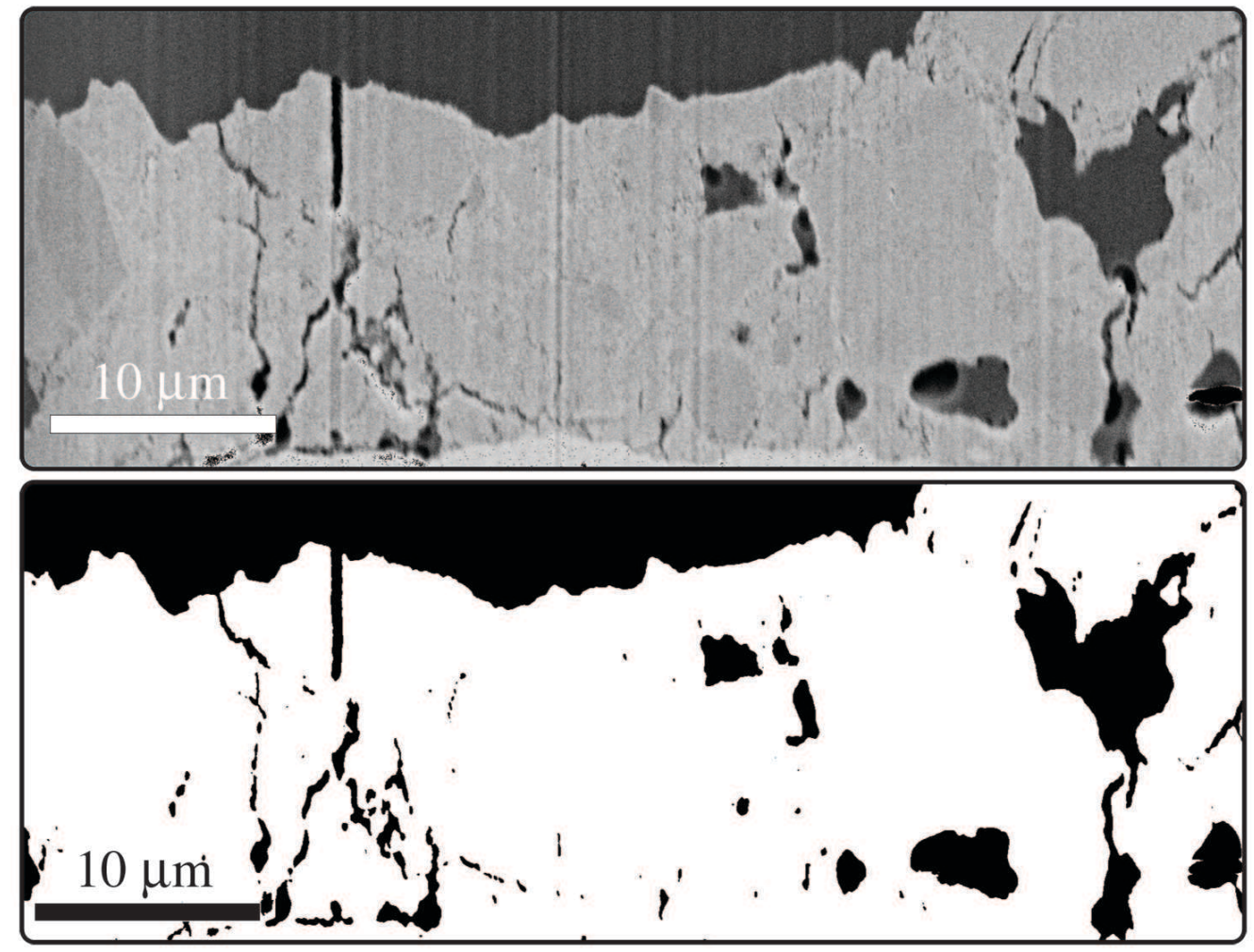

Figure 2: A sample of FIB-SEM image for catalyst reconstruction (top) and the filtered image used for three-dimensional reconstruction (bottom). 
Catalyst surface in contact

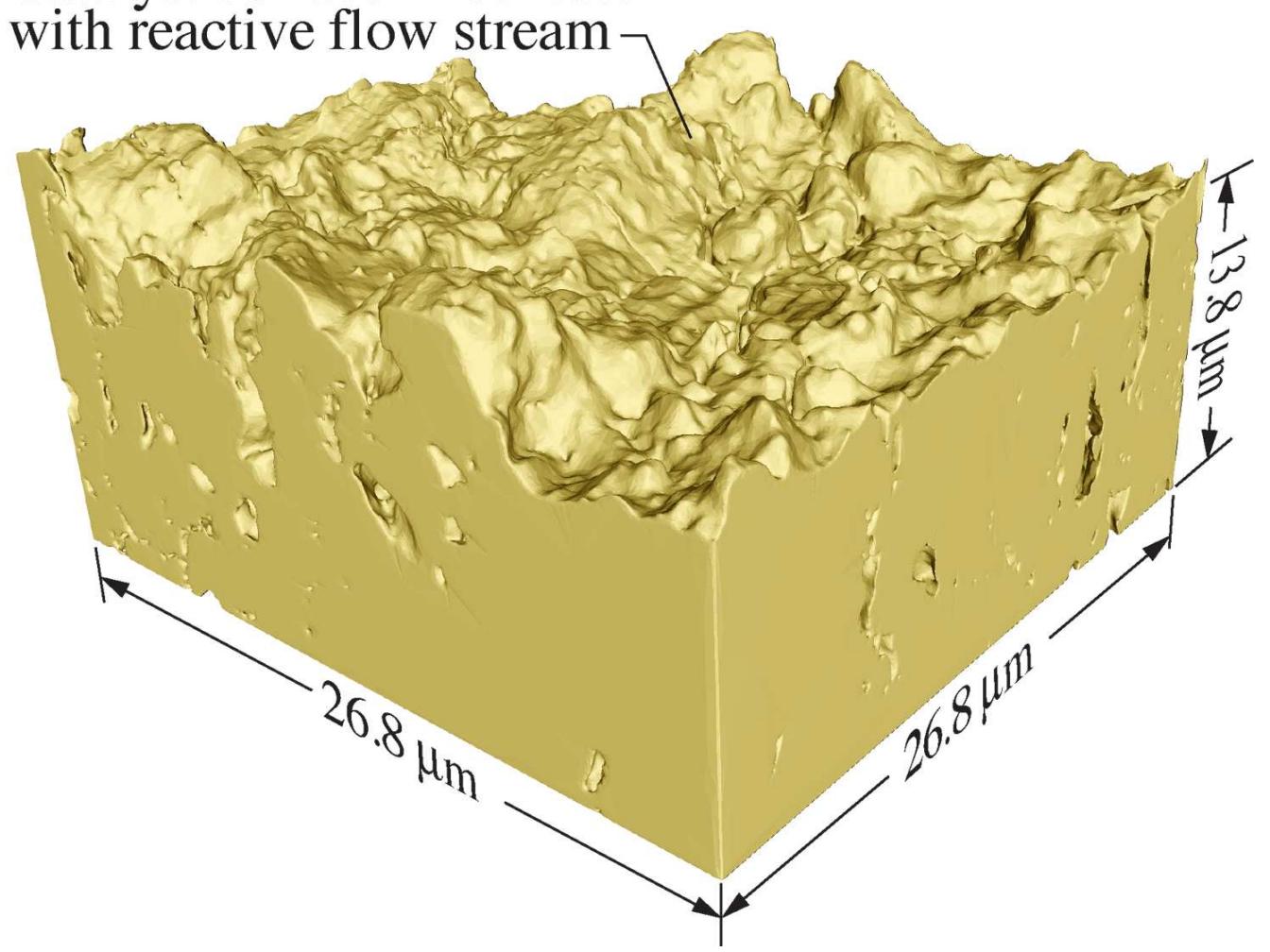

Figure 3: Three-dimensional reconstruction of a small section of catalyst washcoat. 


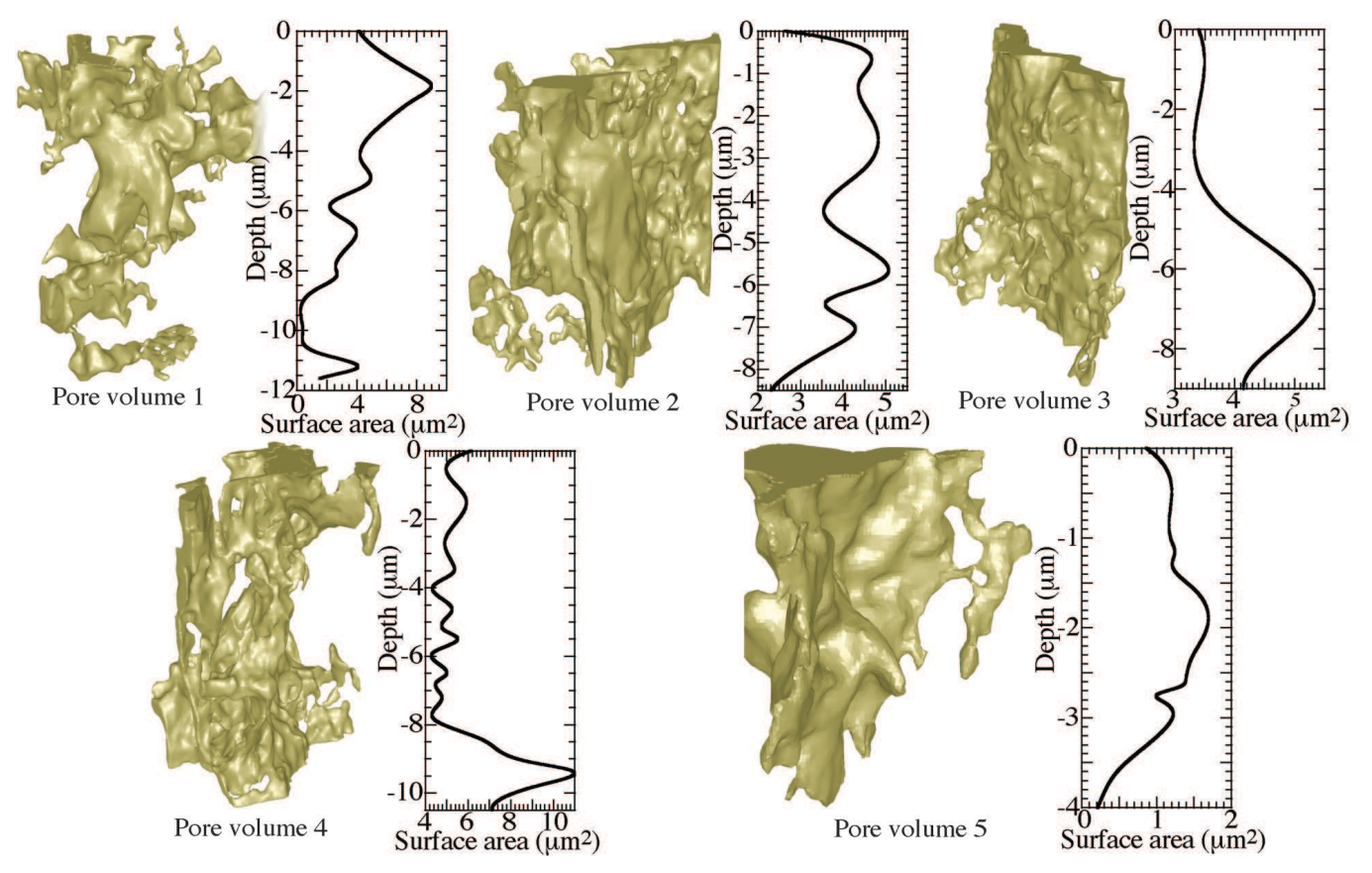

Figure 4: Microstructural pore volumes for five selected pores and their respective surface areas as functions of depth. 


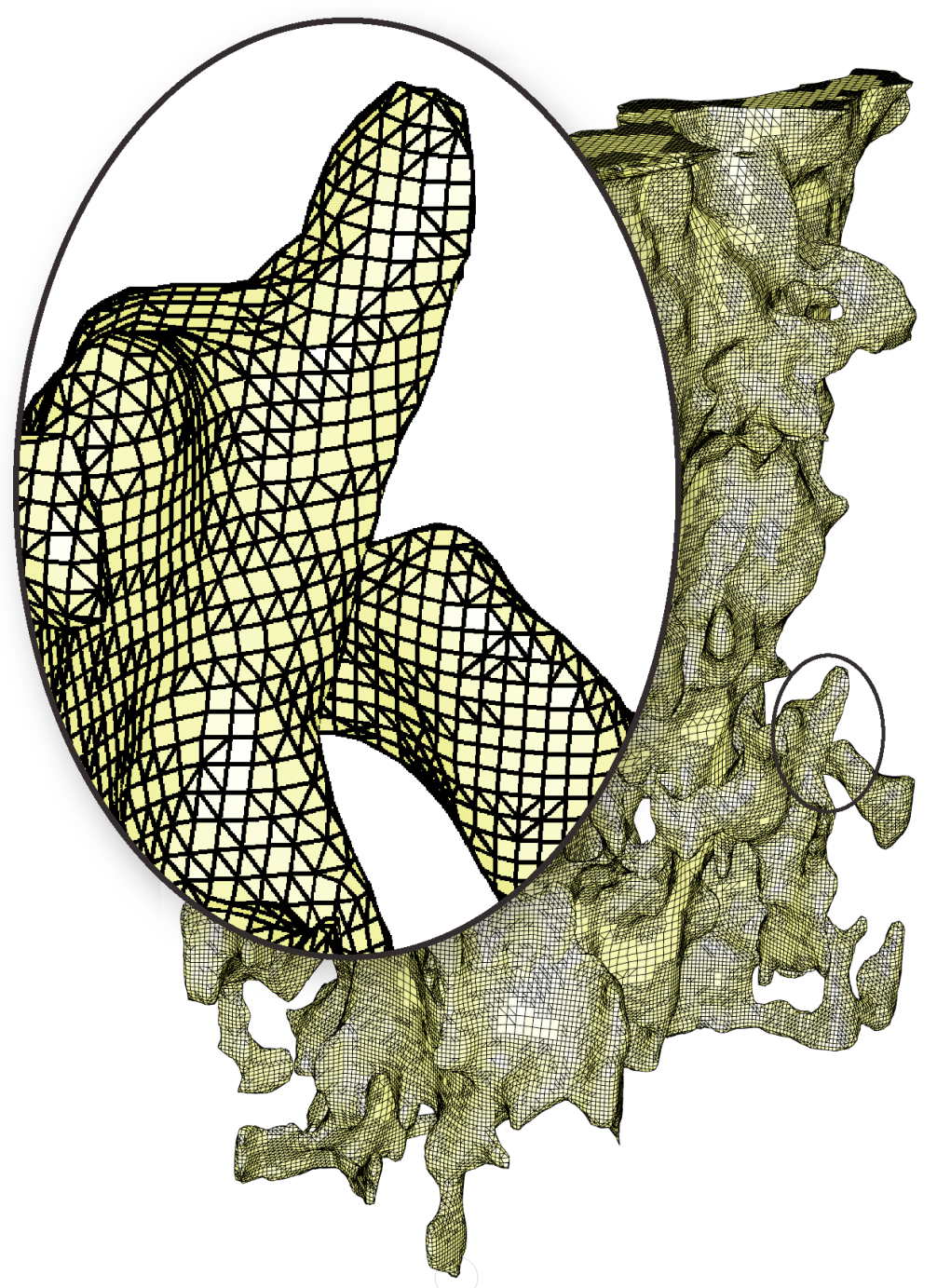

Figure 5: An example of a generated cut-cell mesh created in ANSYS T-GRID for Pore Volume 3. 


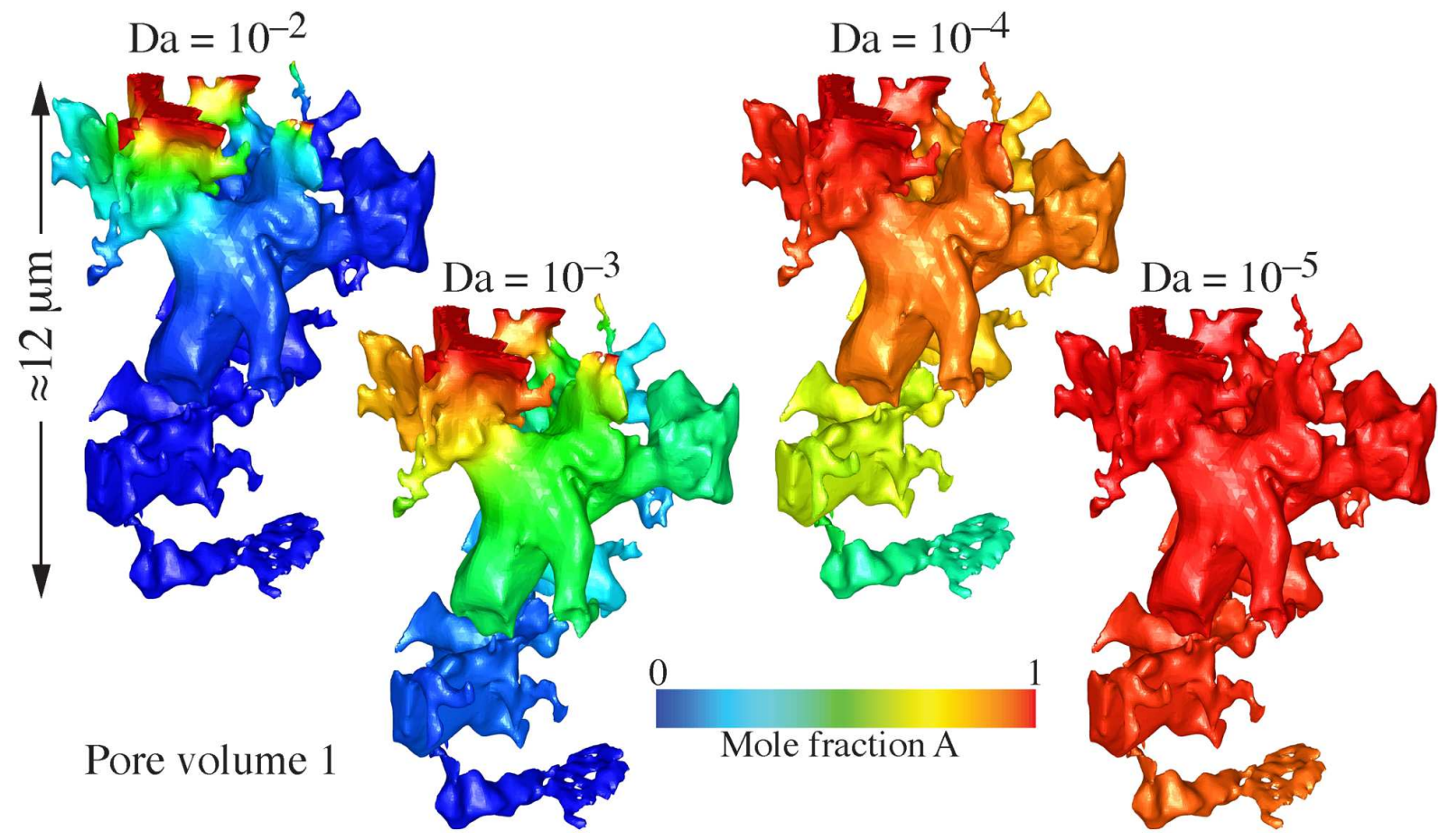

Figure 6: Predicted reactant mole fractions within Pore Volume 1 at different Damköhler numbers. 


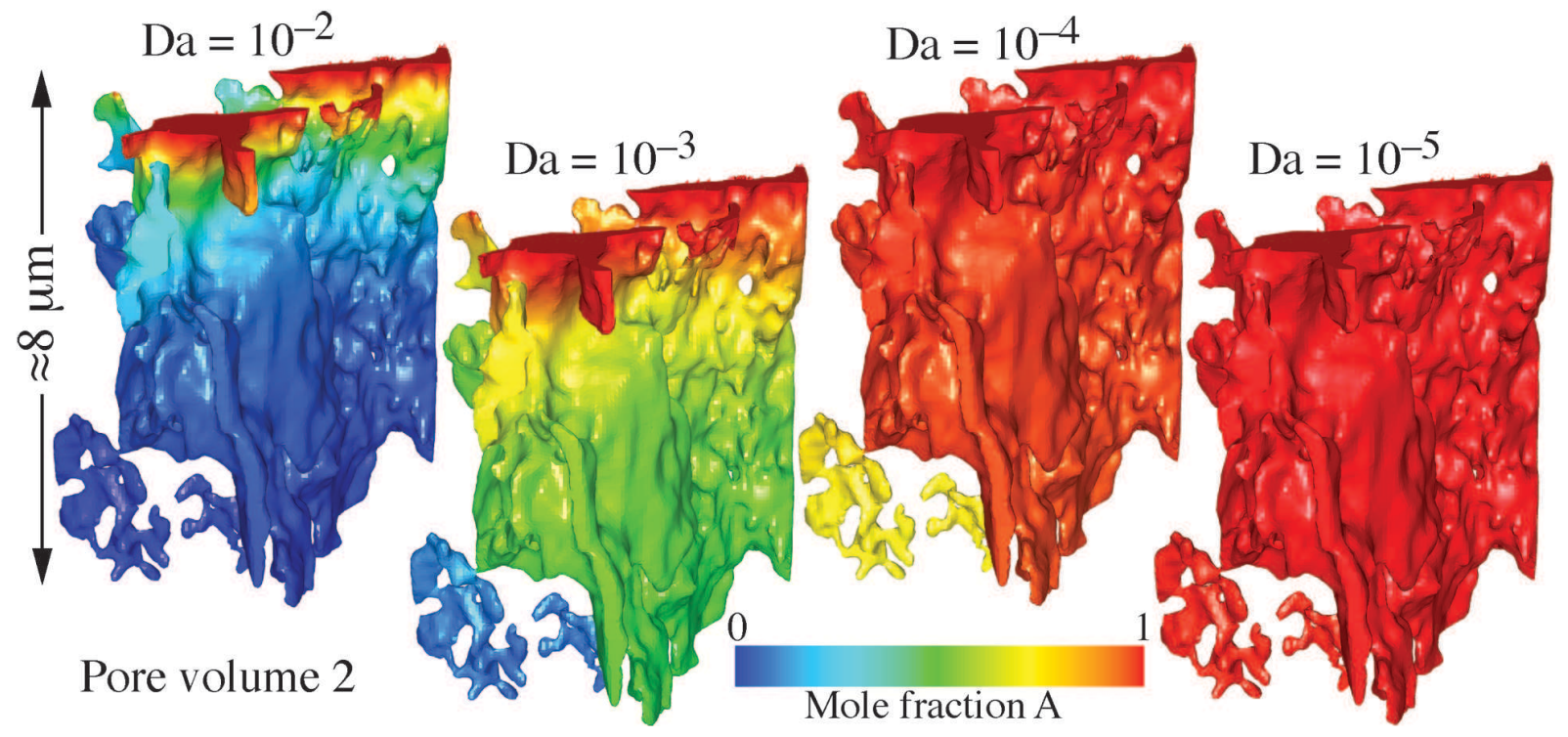

Figure 7: Predicted reactant mole fractions within Pore Volume 2 at different Damköhler numbers. 


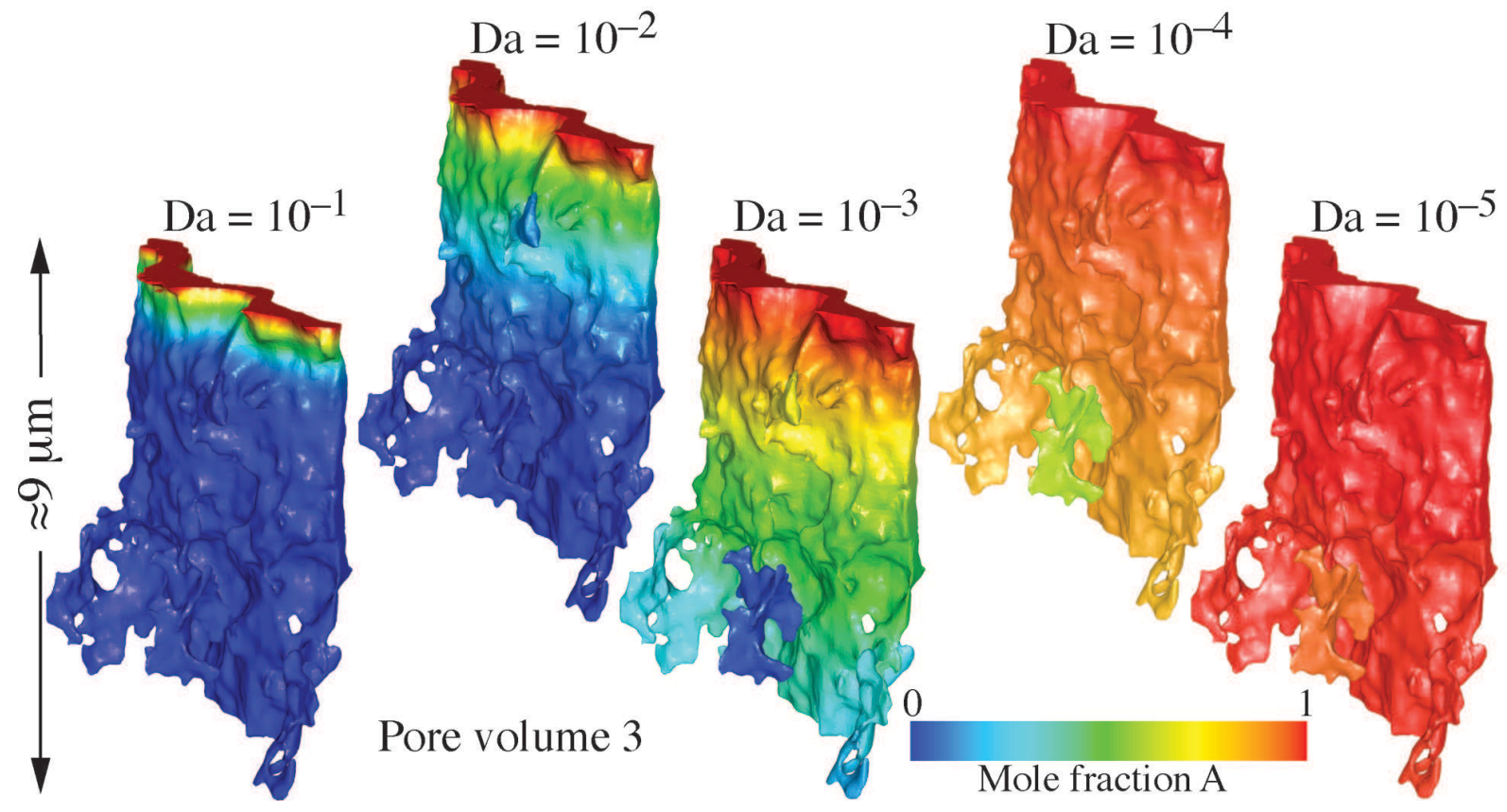

Figure 8: Predicted reactant mole fractions within Pore Volume 3 at different Damköhler numbers. 


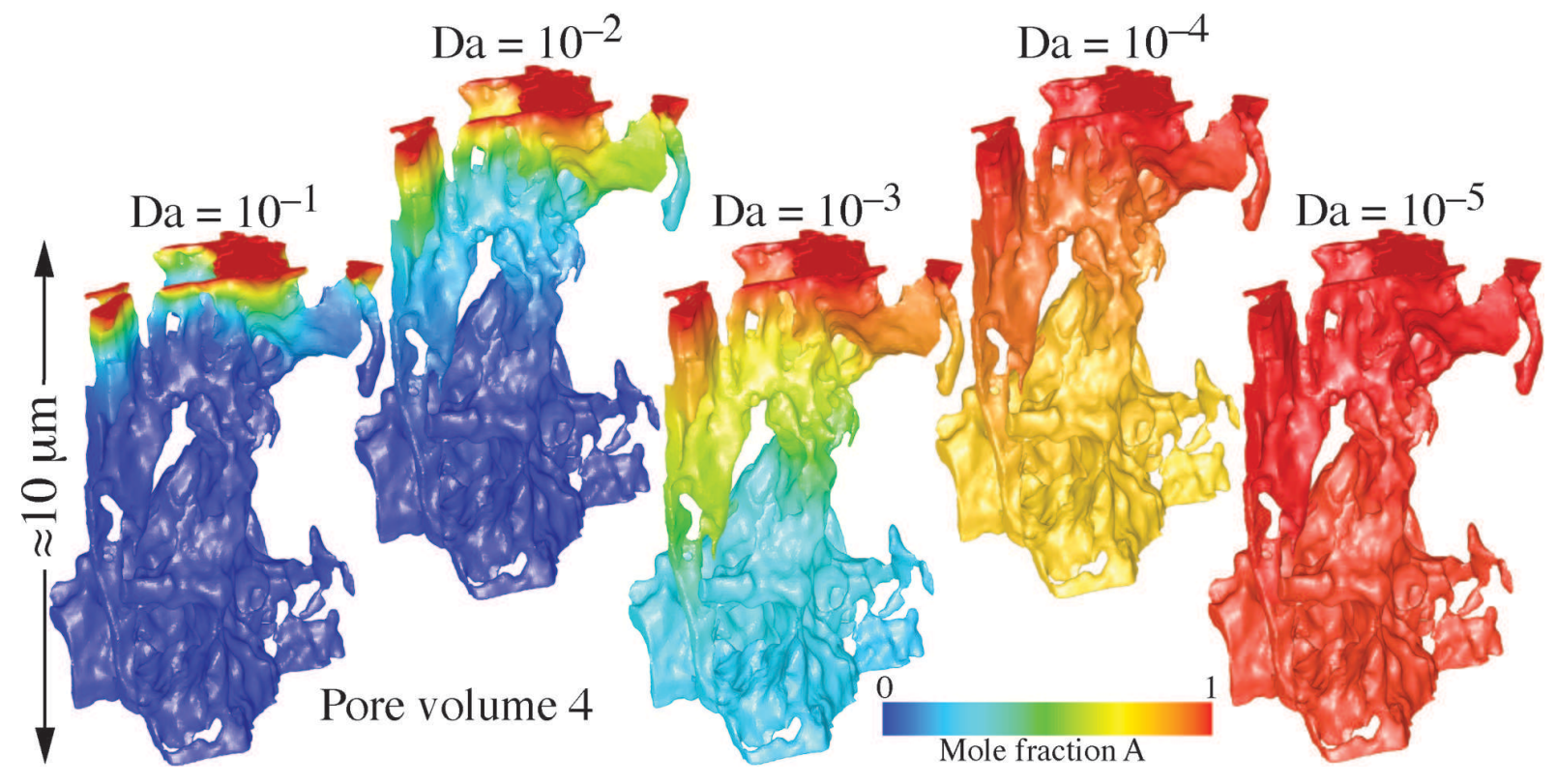

Figure 9: Predicted reactant mole fractions within Pore Volume 4 at different Damköhler numbers. 


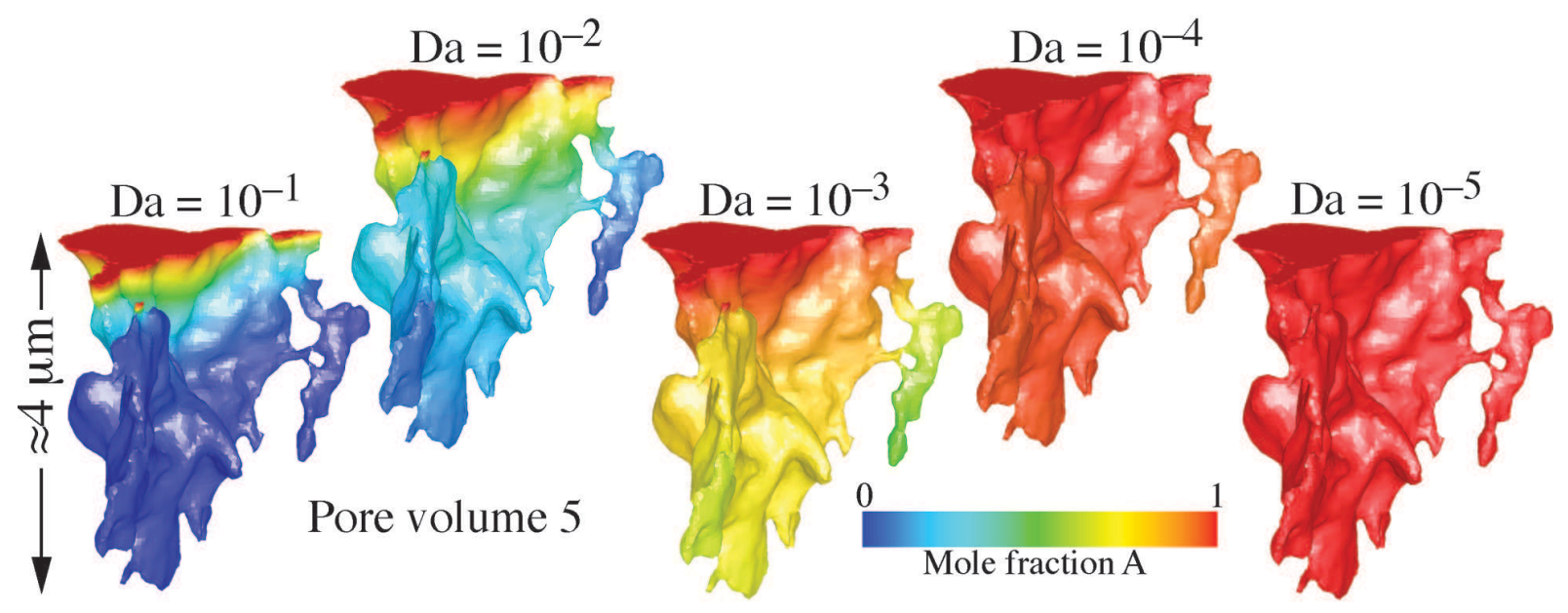

Figure 10: Predicted reactant mole fractions within Pore Volume 5 at different Damköhler numbers. 

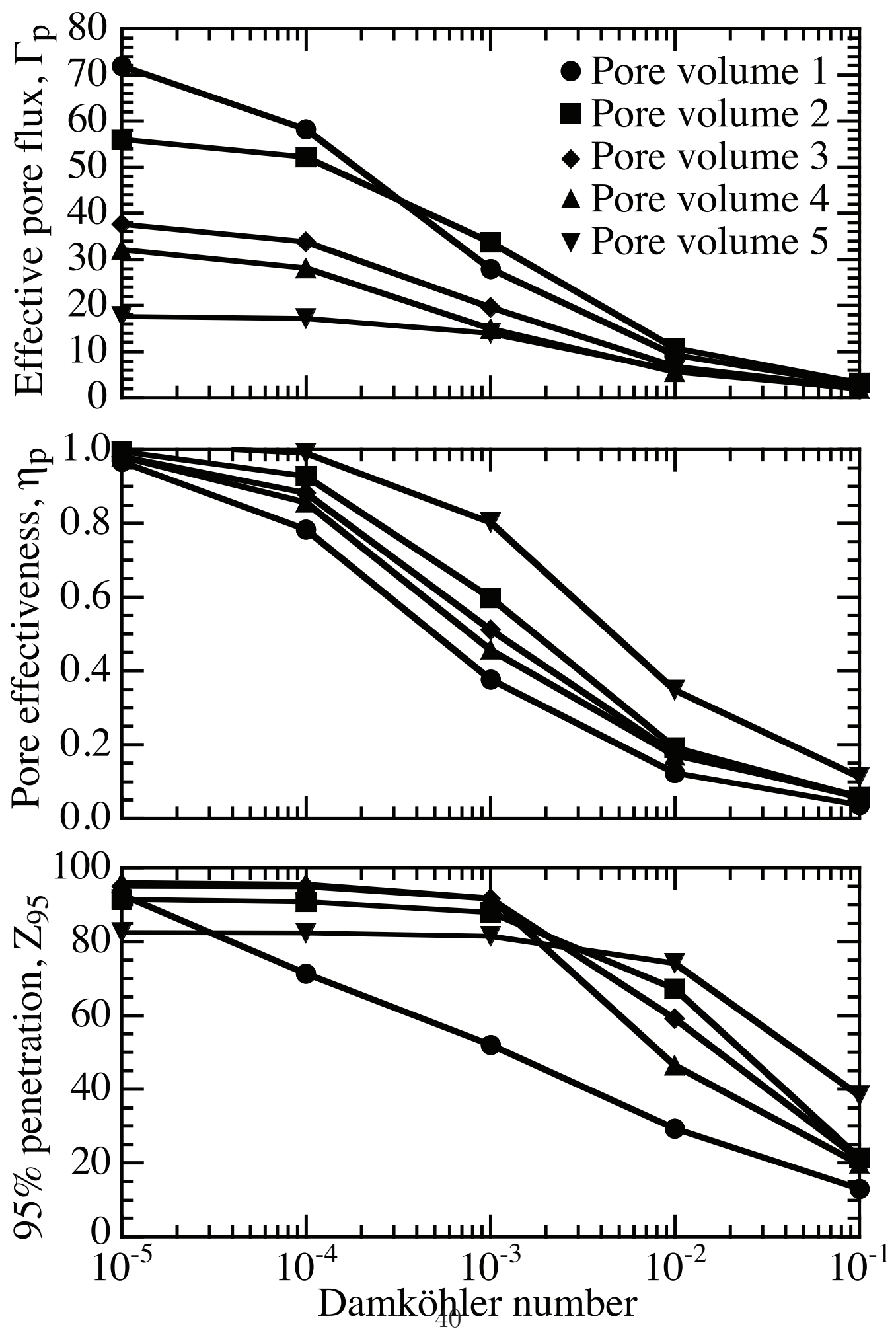

Figure 11: Performance metrics for simulations of the five pore volumes. For a range of Damköhler numbers, the normalized pore flux $\Gamma_{\mathrm{p}}$ (top), the pore effectiveness $\eta_{\mathrm{p}}$ (middle), and reaction depth $\hat{Z}_{95}$ (bottom) are presented. 
${ }_{627}$ List of Tables

${ }_{628} \quad 1$ Reconstructed sample pore area statics . . . . . . . . . . . 42 
Table

Table 1: Reconstructed sample pore area statics Parameter

Pore 1 catalytic surface area, $A_{\mathrm{s}, 1}, \quad 190.5 \mu \mathrm{m}^{2}$

Pore 2 catalytic surface area, $A_{\mathrm{s}, 2} \quad 233.7 \mu \mathrm{m}^{2}$

Pore 3 catalytic surface area, $A_{\mathrm{s}, 3} \quad 203.9 \mu \mathrm{m}^{2}$

Pore 4 catalytic surface area, $A_{\mathrm{s}, 4} \quad 288.9 \mu \mathrm{m}^{2}$

Pore 5 catalytic surface area, $A_{\mathrm{s}, 5} \quad 54.9 \mu \mathrm{m}^{2}$ 